\title{
Novel BN supported bi-metal catalyst for oxydehydrogenation of propane
}

\author{
Jeffrey C.S. Wu*, Shang-Jie Lin \\ Department of Chemical Engineering, National Taiwan University, Taipei 10617, Taiwan, ROC
}

Received 19 August 2007; received in revised form 2 November 2007; accepted 5 November 2007

\begin{abstract}
A novel boron nitride (BN) supported Pt-Sn catalyst was used for the oxydehydrogenation of propane. BN is a graphite-like inert support which provides negligible interaction with metals. The Pt-Sn/BN catalysts were prepared by co-incipient wetness impregnation with various $\mathrm{Sn}$ loadings. A commercial support $\gamma-\mathrm{Al}_{2} \mathrm{O}_{3}$ was chosen to compare with BN. PtSn alloys were formed due to the partially reduced Sn in Pt-Sn/BN catalyst in $\mathrm{H}_{2}$ at $400{ }^{\circ} \mathrm{C}$. Furthermore, the crystalline phases of $\mathrm{PtSn}$ and $\mathrm{SnPt}_{3}$ alloys were also observed from the XRD patterns of Pt-Sn/BN catalysts. However, PtSn alloys were not detected in $\mathrm{Pt}-\mathrm{Sn} / \gamma-\mathrm{Al}_{2} \mathrm{O}_{3}$ by XRD. The $\mathrm{Sn}$ addition clearly improved the activity and propylene selectivity of $\mathrm{Pt}-\mathrm{Sn} / \mathrm{BN}$ at $600^{\circ} \mathrm{C}$. The more the Sn loading, the higher the selectivity and yield of propylene were. A maximum yield of propylene (38.3\%) was achieved on Pt-Sn $(0.75 \mathrm{wt} \%) / \mathrm{BN}$ catalyst at the start of reaction. The catalysts, $\mathrm{Pt}-\mathrm{Sn} / \gamma-\mathrm{Al}_{2} \mathrm{O}_{3}$, deactivated more rapidly than Pt-Sn/BN. The activity and selectivity enhancement are attributed to the formation of PtSn and/or $\mathrm{SnPt}_{3}$ alloy particles on the BN support. Compared with the hydrophilic $\gamma-\mathrm{Al}_{2} \mathrm{O}_{3}$, the hydrophobic $\mathrm{BN}$ surface can expel $\mathrm{H}_{2} \mathrm{O}$ during the oxidation of hydrogen resulting in the activity increase.
\end{abstract}

(C) 2007 Elsevier B.V. All rights reserved.

Keywords: Oxidative dehydrogenation; Propane; Propylene; Boron nitride; Pt; Sn

\section{Introduction}

Propane dehydrogenation has been extensively studied for a long time in the chemical industry. However, this reaction is limited by thermodynamic equilibrium, and requires heat due to endothermic dehydrogenation. In practice, elevated temperatures help to increase conversion but also decrease the propylene selectivity and cause coking on the catalysts. Traditional Houdry process used three reactors to switch between dehydrogenation, decoking and purge. Oxydehydrogenation (or oxidative dehydrogenation) offers remarkable advantages by no thermodynamic limitation and overcomes the heat supply by its exothermic oxidation. The removal of hydrogen by forming water can effectively overcome the thermodynamic constraint at all temperatures of operation. However, two issues need to be considered in the operation of oxydehydrogenation, i.e., safety and economy. The oxygen level is required to be below the explosion limit in the feed in order to have safe operation. To prevent the loss of products, the oxidation of hydrocarbons, i.e., propane

\footnotetext{
* Corresponding author. Tel.: +886 223631994; fax: +886 223623040. E-mail address: cswu@ntu.edu.tw (J.C.S.Wu).
}

and propylene, needs to be kept at a minimum. These two issues still remain challenges, and so far the oxydehydrogenation of propane has not reached the commercial level [1].

One difficulty of propane oxydehydrogenation is that propylene oxidizes much more easily than that of propane. In addition, the cracking of propane becomes significant above $700{ }^{\circ} \mathrm{C}$, which decreases the selectivity of propylene [1]. Stern and Grasselli reported a propylene selectivity up to $60 \%$ at $26.6 \%$ conversion using metal tungstate and molybdate catalysts [2]. Vanadium-magnesium mixed oxide was used as a selective catalyst for oxydehydrogenation by Solsona et al. The selectivity of propylene was $40.4 \%$ at $36.7 \%$ conversion using a feed of $4 \%$ propane with $8 \%$ oxygen in $\mathrm{He}$ at $550^{\circ} \mathrm{C}$ [3]. Nowinska et al. applied transition-metal exchanged ZSM-5 catalysts to perform propane oxydehydrogenation. The selectivity of propylene significantly increased to near $70 \%$ at $22 \%$ conversion at $370{ }^{\circ} \mathrm{C}$ using $\mathrm{N}_{2} \mathrm{O}$ as oxidant, however, the selectivity decreased substantially when air was used as oxidant [4].

The selectivity of propylene can be very high in the propane dehydrogenation using bi-metallic catalysts. More than $95 \%$ of propylene selectivity on supported PtSn catalysts has been demonstrated at 20-60\% conversion when hydrogen was supplied in the feed [5-8]. Coking can be significantly reduced by $\mathrm{Sn}$ 
addition, thus increasing the catalytic stability of the catalysts. However, without $\mathrm{H}_{2}$ in the feed, the activity and propylene selectivity declined quickly due to serious coke formation.

Materials traditionally used as supports are insulating oxides such as $\mathrm{SiO}_{2}, \gamma-\mathrm{Al}_{2} \mathrm{O}_{3}, \mathrm{~V}_{2} \mathrm{O}_{5}, \mathrm{TiO}_{2}$ and various zeolites. These oxides possess large surface area, numerous acidic/basic sites, and metal-support interaction that offer particular catalytic activity for many reactions. Metal oxides have also been thoroughly studied and employed in the chemical industry for decades. On the other hand, non-oxide materials possess many unique properties unlike metal oxides, such as high thermal conductivity, acid-base resistance, hydrophobicity and possibly negligible metal-support interaction. Boron nitride (BN) has been used as catalyst support recently $[9,10]$. The graphite-like hexagonal $\mathrm{BN}$ is the most stable BN isomer under ambient conditions [11]. In general, BN is inert for catalytic reaction. In a supported metal system such as $\mathrm{Pt} / \mathrm{BN}, \mathrm{BN}$ has been shown to have a negligible interaction with $\mathrm{Pt}$ in the catalytic oxidation [9]. The easy migration of Pt particles occurred on the crystalline face of $\mathrm{BN}$ due to the weaker adhesion between the crystalline face and Pt $[9,10]$. Such effect may promote metal sintering and lead to the formation of a bimetallic alloy, a favorable active site for the selective hydrogenation of $\alpha$, $\beta$-unsaturated aldehyde to unsaturated alcohol $[12,13]$. Our previous study indicated that $\mathrm{PtSn}$ alloy on $\mathrm{BN}$ support significantly enhanced the selectivity toward crotyl alcohol in crotonaldehyde hydrogenation [14]. In this study, the oxydehydrogenation of propane is selected to explore the enhanced selectivity toward propylene by the bimetallic clusters on the unique BN support.

\section{Experimental}

\subsection{Catalysts preparation}

Hexagonal-BN was obtained from the High Performance Materials Inc. (Taiwan). It was crystallized at roughly $800^{\circ} \mathrm{C}$ during synthesis, a temperature lower than the typical $1000^{\circ} \mathrm{C}$. Gamma alumina $\left(\gamma-\mathrm{Al}_{2} \mathrm{O}_{3}\right)$, a commonly used oxide support, was obtained from Merck (USA) and used for comparison. Precursor salt, $\mathrm{H}_{2} \mathrm{PtCl}_{6} \cdot 6 \mathrm{H}_{2} \mathrm{O}$, with approximately $40 \mathrm{wt} . \%$ platinum, and pure $\mathrm{SnCl}_{2}$ were purchased from Alfa Aesar (USA). Methanol was chosen as the diluting solvent for improved soaking of the hydrophobic BN support. The supported Pt-Sn catalysts were prepared utilizing a co-incipient wetness method. The quantity of methanol required to completely fill the support's pore volume was predetermined. Calculated amounts of $\mathrm{Pt}$ and $\mathrm{Sn}$ precursor salts were dissolved in methanol to obtain the desired metal loadings. After the coincipient wetness process was applied, catalysts were air-dried at room temperature for $24 \mathrm{~h}$; these are referred to as fresh catalysts. All Pt loading was fixed at $1.1 \mathrm{wt} \%$; Sn loadings varied from 0.25 to $0.75 \mathrm{wt} \%$. The X.XX wt $\%$ of Sn loading was assigned as Pt$\mathrm{Sn}(\mathrm{X} . \mathrm{XX}) / \mathrm{BN}$. In addition, $1.1 \mathrm{wt} \% \mathrm{Pt} / \mathrm{BN}, 1.1 \mathrm{wt} \% \mathrm{Pt} / \gamma-\mathrm{Al}_{2} \mathrm{O}_{3}$ and a series of $\mathrm{Pt}-\mathrm{Sn} / \gamma-\mathrm{Al}_{2} \mathrm{O}_{3}$ catalysts were also prepared for comparison. The detailed incipient wetness procedure is described in literature [15].

\subsection{Characterization}

The specific surface area of the support was measured by $\mathrm{N}_{2}$ adsorption in Micromeritics ASAP 2010. The particle sizes and distributions of $\mathrm{BN}$ and $\gamma-\mathrm{Al}_{2} \mathrm{O}_{3}$ were measured by laser-light scattering. $\gamma-\mathrm{Al}_{2} \mathrm{O}_{3}$ was suspended and dispersed ultrasonically in water for $3 \mathrm{~min}$. BN was dispersed in ethanol due to its hydrophobicity. Coulter LS 230 was used to measured the scattering of incidental light at the $90^{\circ}$ position, thereafter the particle size was calculated using the Fraunhofer equation. Hydrogen chemisorption was measured on Micromeritics Autochem II. Fresh catalyst was reduced in $10 \% \mathrm{H}_{2} / \mathrm{Ar}$ flow at $400^{\circ} \mathrm{C}$ for $1 \mathrm{~h}$ then cooled down to $50^{\circ} \mathrm{C}$ under He purge before pulse chemisorption. Each pulse contained $0.05 \mathrm{ml}$ of $10 \% \mathrm{H}_{2} / \mathrm{Ar}$ and the time between pulses was $3 \mathrm{~min}$. The amount of $\mathrm{H}_{2}$ chemisorption was taken to determine $\mathrm{Pt}$ dispersion by assuming $\mathrm{H}: \mathrm{Pt}=1$. A transmission electron microscope (TEM, Hitachi H-7100) was employed to observe the shape of BN and the appearance of PtSn particles dispersed on the support. The crystalline phases of catalysts were identified by X-ray diffraction (XRD). The XRD equipment, type M03XHF22 from the Material Analysis and Characterization Company, was operated at $40 \mathrm{kV}$, with a $1.54056 \AA \mathrm{X}$-ray wavelength from a Cu target, and a scanning speed of $0.5^{\circ} \mathrm{min}^{-1}$. X-ray photoelectron spectroscopy (XPS) was conducted on a spectrometer of VG Microtech MT500. The measured binding energy was referenced to carbon (1s) at $285.6 \mathrm{eV}$.

\subsection{Oxydehydrogenation of propane}

Fresh catalyst $(0.3 \mathrm{~g})$ was charged in the middle of a straighttube quartz reactor with a $10-\mathrm{mm}$ i.d. The catalyst was reduced for $2 \mathrm{~h}$ at $400{ }^{\circ} \mathrm{C}$, using pure hydrogen $(99.999 \%)$ in the reactor and then increased to the reaction temperature under He purge before switching to the reactant mixture. The reactant mixture was composed by mixing pure propane and air. The molar ratio of propane/air mixture was maintained at $8 / 2$ and passed through the reactor at $23.8 \mathrm{ml} / \mathrm{min}\left(\mathrm{WHSV}=6.8 \mathrm{~h}^{-1}\right)$ under atmospheric pressure. The concentration of propane in the reactant mixture was accurately adjusted by tuning the flowmeter of propane. The concentration was further confirmed by an on-line GC (Agilent GC6890) before reaction. The reaction temperature was maintained at $600^{\circ} \mathrm{C}$ in a tubular furnace. A thermocouple was placed in the center of the catalyst bed to record the reaction temperature and to control the furnace. The products of oxydehydrogenation were measured by the on-line GC equipped with a $30 \mathrm{~m}$ GS-Alumina capillary column using FID and TCD detectors in series.

The conversion of propane and the selectivity of products were calculated using Eqs. (1) and (2). The yield of propylene was calculated by multiplying the conversion by its selectivity in Eq. (3). In order to estimate the oxidation loss in the oxydehydrogenation, the overall carbon balance was calculated based on the difference of input and output total hydrocarbons.

conversion $(\%)=1-\frac{C_{\text {propane }} \text { Out }}{C_{\text {propane }} \text { In }} \times 100 \%$ 
Table 1

$\mathrm{H}_{2}$ chemisorption and $\mathrm{Pt}$ dispersion and particle size

\begin{tabular}{llc}
\hline Catalyst & Hydrogen $(\mathrm{ml} / \mathrm{g})$ & Metal dispersion $^{\mathrm{a}}(\%)$ \\
\hline $\mathrm{Pt} / \mathrm{BN}$ & 0.095 & 16.7 \\
$\mathrm{Pt}-\mathrm{Sn}(0.25) / \mathrm{BN}$ & 0.110 & 17.2 \\
$\mathrm{Pt}-\mathrm{Sn}(0.50) / \mathrm{BN}$ & 0.135 & 21.5 \\
$\mathrm{Pt}-\mathrm{Sn}(0.75) / \mathrm{BN}$ & 0.005 & 0.7 \\
$\mathrm{Pt} / \gamma-\mathrm{Al}_{2} \mathrm{O}_{3}$ & 0.640 & 100.9 \\
$\mathrm{Pt}-\mathrm{Sn}(0.25) / \gamma-\mathrm{Al}_{2} \mathrm{O}_{3}$ & 0.225 & 35.7 \\
$\mathrm{Pt}-\mathrm{Sn}(0.50) / \gamma-\mathrm{Al}_{2} \mathrm{O}_{3}$ & 0.255 & 40.1 \\
$\mathrm{Pt}-\mathrm{Sn}(0.75) / \gamma-\mathrm{Al}_{2} \mathrm{O}_{3}$ & 0.100 & 15.6 \\
\hline
\end{tabular}

Reduced at $400{ }^{\circ} \mathrm{C}$ in $\mathrm{H}_{2}$ before chemisorption.

a Assume $\mathrm{H}: \mathrm{Pt}=1$.

selectivity $(\%)=\frac{C_{\text {product }}}{\sum C_{\text {products }}} \times 100 \%$

$\operatorname{yield}(\%)=\frac{\text { conversion }(\%) \times \operatorname{selectivity}(\%)}{100}$

\section{Results and discussion}

\subsection{Characteristics of catalysts}

The specific surface areas of $\mathrm{BN}$ and $\gamma-\mathrm{Al}_{2} \mathrm{O}_{3}$ are 46.3 and $111.9 \mathrm{~m}^{2} / \mathrm{g}$, respectively. The mean particle size of $\mathrm{BN}$ and $\gamma$ $\mathrm{Al}_{2} \mathrm{O}_{3}$ are calculated to be 3.7 and $77.4 \mu \mathrm{m}$, respectively, from the results of laser-light scattering. Table 1 summarizes the results of $\mathrm{H}_{2}$ chemisorption on all catalysts. The amounts of $\mathrm{H}_{2}$ chemisorption on $\gamma-\mathrm{Al}_{2} \mathrm{O}_{3}$ catalysts are higher than those on $\mathrm{BN}$ catalysts due to the nature of supports. Low Pt dispersion on $\mathrm{BN}$ is because the easy migration of Pt creates large particles on the $\mathrm{BN}$ surface during $\mathrm{H}_{2}$ reduction. The $\mathrm{H}_{2}$ chemisorption on $\gamma$ $\mathrm{Al}_{2} \mathrm{O}_{3}$ is suppressed with increasing $\mathrm{Sn}$ loading. The amounts of $\mathrm{H}_{2}$ chemisorption on $\mathrm{Pt}-\mathrm{Sn}$ catalysts decrease due to $\mathrm{Sn}$ dilution or coverage of the Pt surface in these catalysts. Pt-Sn(0.75)/BN has the lowest dispersion implying a high coverage of $\mathrm{Sn}$ in metal particles. The monometallic Pt dispersion on $\gamma-\mathrm{Al}_{2} \mathrm{O}_{3}$ shows more than $100 \%$ possibly due to $\mathrm{H}_{2}$ spillover.

Fig. 1(a) shows the XRD patterns of Pt-Sn/BN catalysts which were $\mathrm{H}_{2}$ reduced at $400{ }^{\circ} \mathrm{C}$. The diffraction pattern of $\mathrm{Sn} / \mathrm{BN}$ is the same as that of pure BN. No characteristic peak of $\mathrm{Sn}$ is found indicating that either monometallic Sn particles do not exist or are very small in size. The major characteristic peaks of $\mathrm{Pt}$ are clearly shown at $39.8^{\circ}, 46.2^{\circ}$ and $67.5^{\circ}$. The crystalline phases of $\mathrm{PtSn}$ and $\mathrm{SnPt}_{3}$ alloys are also observed with various $\mathrm{Sn}$ loading catalysts. The characteristic peak of $\mathrm{SnPt}_{3}$ is at $38.9^{\circ}$ on $\mathrm{Pt}-\mathrm{Sn}(0.5) / \mathrm{BN}$ and $\mathrm{Pt}-\mathrm{Sn}(0.25) / \mathrm{BN}$ catalysts. Pt$\mathrm{Sn}(0.75) / \mathrm{BN}$ contains only the PtSn peaks at $30.0^{\circ}$ and $62.3^{\circ}$ [16]. The rest of the characteristic peaks of $\mathrm{SnPt}_{3}$ or $\mathrm{PtSn}$ are not marked because they are overlapped with those of Pt or BN. A small portion of Pt particles can be found on $\mathrm{Pt}-\mathrm{Sn}(0.25) / \mathrm{BN}$ and $\mathrm{Pt}-\mathrm{Sn}(0.5) / \mathrm{BN}$, as shown in their XRD patterns. With a higher Sn loading, the characteristic peaks of $\mathrm{Pt}$ on $\mathrm{Pt}-\mathrm{Sn}(0.75) / \mathrm{BN}$ are diminished indicating that no individual $\mathrm{Pt}$ particles are present. Therefore, the PtSn and/or $\mathrm{SnPt}_{3}$ alloys are formed during the $\mathrm{H}_{2}$ reduction. Fig. 1(b) shows the XRD patterns of $\mathrm{Pt} / \gamma-\mathrm{Al}_{2} \mathrm{O}_{3}$, $\mathrm{Sn} / \gamma-\mathrm{Al}_{2} \mathrm{O}_{3}$ and $\mathrm{Pt}-\mathrm{Sn} / \gamma-\mathrm{Al}_{2} \mathrm{O}_{3}$ series catalysts, which are $\mathrm{H}_{2}$
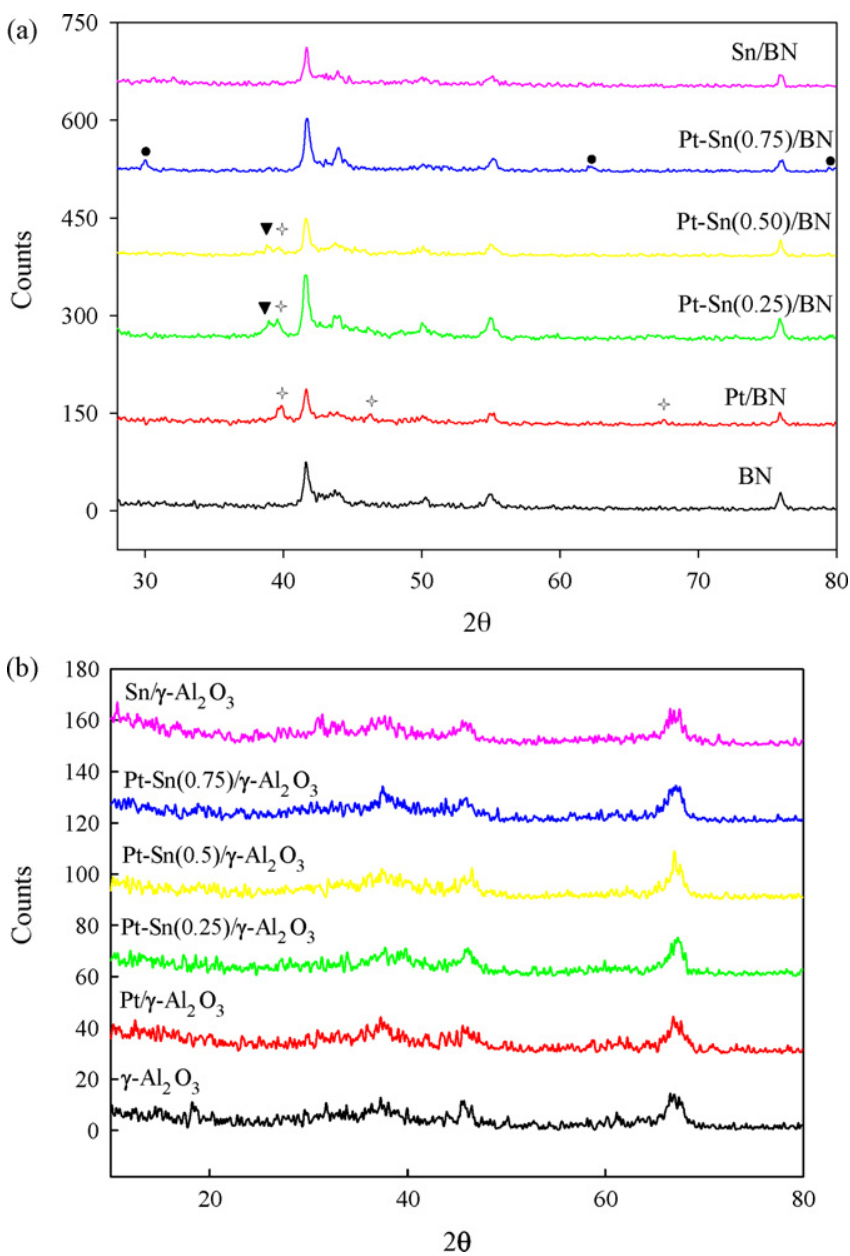

Fig. 1. (a) $\mathrm{XRD}$ of $\mathrm{BN}, \mathrm{Pt} / \mathrm{BN}$ and $\mathrm{PtSn} / \mathrm{BN}, \mathrm{H}_{2}$ reduced at $400{ }^{\circ} \mathrm{C}$ for $2 \mathrm{~h} \mathrm{Pt}$ (»), $\mathrm{SnPt}_{3}(\boldsymbol{\nabla}), \mathrm{PtSn}(\boldsymbol{\bullet})$. (b) XRD of $\gamma-\mathrm{Al}_{2} \mathrm{O}_{3}, \mathrm{Pt} / \gamma-\mathrm{Al}_{2} \mathrm{O}_{3} \mathrm{Sn} / \gamma-\mathrm{Al}_{2} \mathrm{O}_{3}$ and $\mathrm{PtSn} / \gamma-\mathrm{Al}_{2} \mathrm{O}_{3}, \mathrm{H}_{2}$ reduced at $400{ }^{\circ} \mathrm{C}$ for $2 \mathrm{~h}$.

reduced at $400{ }^{\circ} \mathrm{C}$, are the same as the background diffraction pattern of sole $\gamma-\mathrm{Al}_{2} \mathrm{O}_{3}$. The metal particles are too small to be observed in the XRD, revealing highly dispersed Pt and/or Pt-Sn particles on the $\gamma-\mathrm{Al}_{2} \mathrm{O}_{3}$ support.

Fig. 2(a and b) show the TEM micrographs of Pt/BN and $\mathrm{Pt}-\mathrm{Sn}(0.75) / \mathrm{BN}$. Metal particles with sizes $8-15 \mathrm{~nm}$ can be observed in Fig. 2(a), which indicates that most of the Pt particles are located on the edges of BN particles. The metal particles are difficult to be identified on Pt-Sn(0.75)/BN as shown in Fig. 2(b). Most likely, PtSn alloy may be formed on the BN support.

Fig. 3 shows the XPS of the fresh and $\mathrm{H}_{2}$ reduced Pt$\mathrm{Sn}(0.75) / \mathrm{BN}$ and $\mathrm{Sn} / \mathrm{BN}$ catalysts, respectively. The binding energy of $\mathrm{Sn} 3 \mathrm{~d}_{5 / 2}$ on $\mathrm{Sn} / \mathrm{BN}$ is at $486.4 \mathrm{eV}$ indicating sole $\mathrm{Sn}$ cannot be $\mathrm{H}_{2}$ reduced at $400{ }^{\circ} \mathrm{C}$, thus remains in $\mathrm{Sn}^{2+}$ state. On $\mathrm{Pt}-\mathrm{Sn}(0.75) / \mathrm{BN}$, a portion of $\mathrm{Sn}$ is reduced after $\mathrm{H}_{2}$ reduction at $400{ }^{\circ} \mathrm{C}$, and formed PtSn alloy as indicated by it's binding energy of $\mathrm{Sn} 3 \mathrm{~d}_{5 / 2}$ at $483.3 \mathrm{eV}$ [17]. Another portion of $\mathrm{Sn}^{2+}$ is retained as indicated by its binding energy located at $486.4 \mathrm{eV}$. Thus, Sn oxide is sprinkled either on the PtSn alloy or BN support.

The chemical status of $\mathrm{Pt}$ in $\mathrm{Pt}-\mathrm{Sn}(0.75) / \mathrm{BN}$ and $\mathrm{Pt} / \mathrm{BN}$ is shown in Fig. 4. The binding energy of $\mathrm{Pt} 4 \mathrm{f}_{7 / 2}$ in $\mathrm{Pt} / \mathrm{BN}$ is detected at $71.2 \mathrm{eV}$ indicating metal $\mathrm{Pt}^{0}$ after $\mathrm{H}_{2}$ reduction for 
(a)

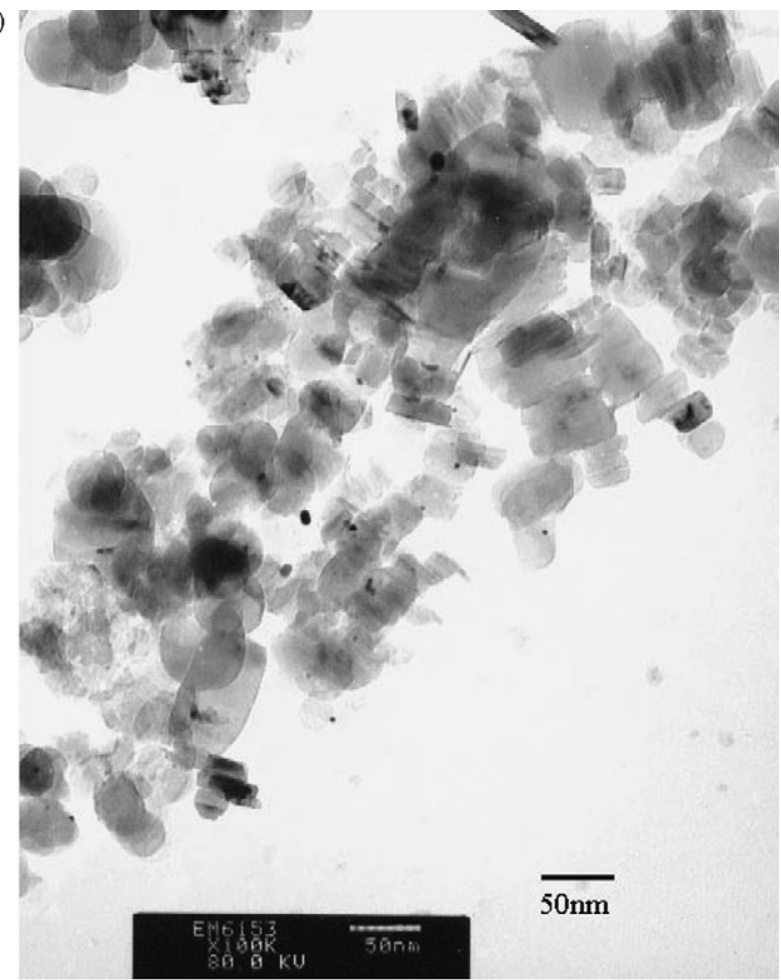

(b)

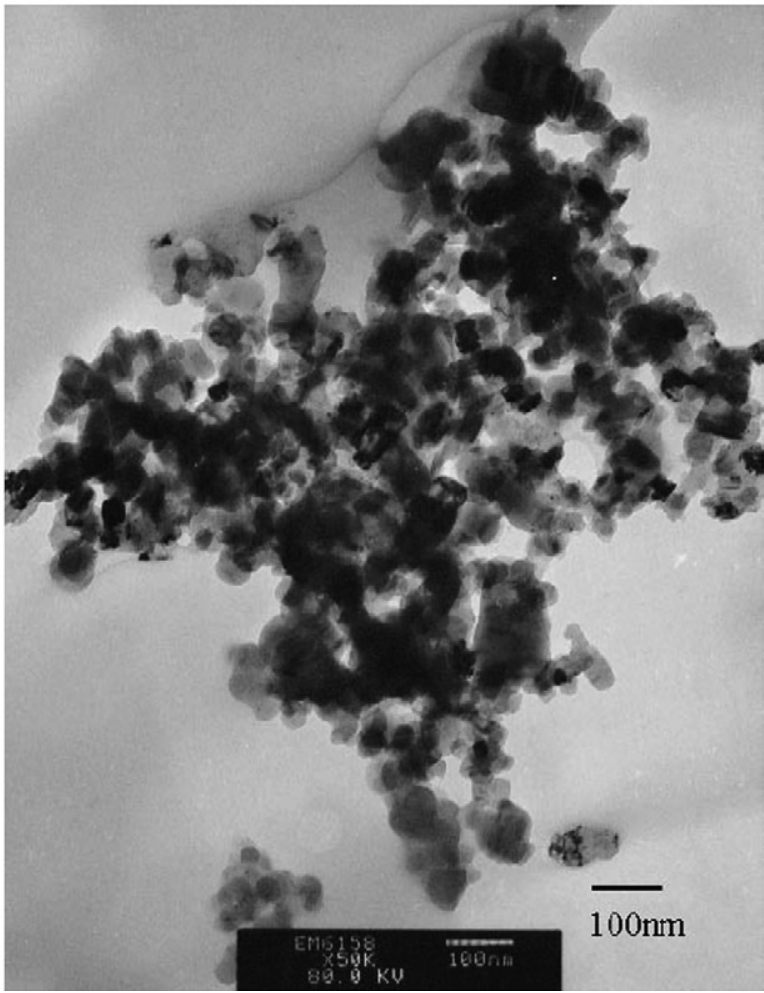

Fig. 2. TEM of (a)Pt/BN and (b)Pt-Sn(0.75)/BN.

$2 \mathrm{~h}$ at $400{ }^{\circ} \mathrm{C}$. The $\mathrm{Pt} 4 \mathrm{f}_{7 / 2}$ of the fresh Pt-Sn(0.75)/BN is located near $73.5 \mathrm{eV}$ indicating the near $\mathrm{Pt}^{2+}$ state [17]. Compared with reduced $\mathrm{Pt} / \mathrm{BN}$, the binding energy of $\mathrm{Pt}$ in the $\mathrm{H}_{2}$ reduced $\mathrm{Pt}-\mathrm{Sn}(0.75) / \mathrm{BN}$ shows a $0.5 \mathrm{eV}$ positive shift to 71.7 revealing surface Pt may be positively charged due to the partially

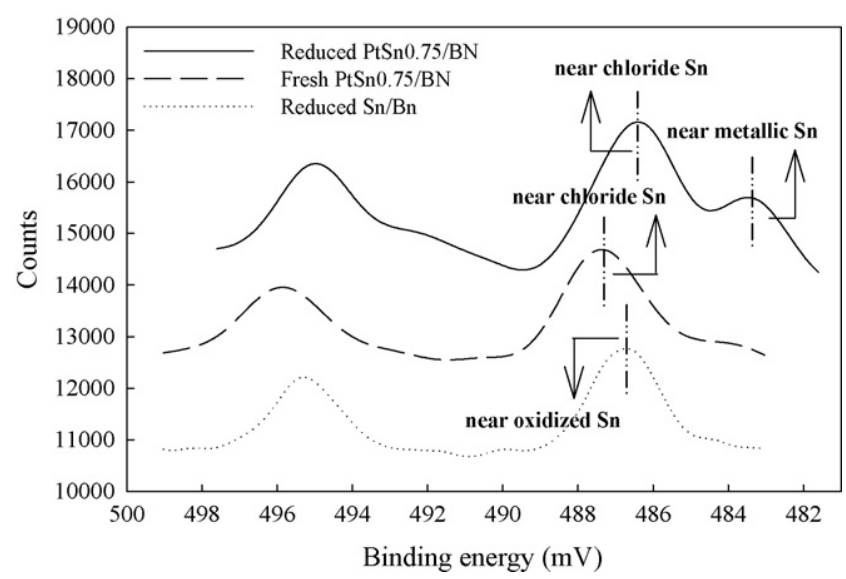

Fig. 3. XPS of Sn 3d on BN support.

surrounding $\mathrm{Sn}^{2+}$ on PtSn alloy [18]. After $\mathrm{H}_{2}$ reduction, the surface $\mathrm{Pt}$ on $\mathrm{Pt}-\mathrm{Sn}(0.75) / \mathrm{BN}$ is mostly reduced but some $\mathrm{Sn}^{2+}$ is still not reducible (Fig. 3).

The $\mathrm{H}_{2}$ reduction of fresh $\mathrm{Pt}-\mathrm{Sn} / \mathrm{BN}$ catalysts were studied by employing TPR in our previous study [14]. The results indicated that the tendency to form Pt-Sn particles was much easier on $\mathrm{BN}$ than on $\gamma-\mathrm{Al}_{2} \mathrm{O}_{3}$. The support of $\gamma-\mathrm{Al}_{2} \mathrm{O}_{3}$ constrains the mobility of $\mathrm{Pt}$ and $\mathrm{Sn}$ during $\mathrm{H}_{2}$ reduction due to the metal-support affinity. It is suspected that no PtSn alloy is formed on the $\gamma-\mathrm{Al}_{2} \mathrm{O}_{3}$ support after $\mathrm{H}_{2}$ reduction at $400{ }^{\circ} \mathrm{C}$.

\subsection{Oxydehydrogenation of propane}

Fig. 5 shows the conversions of oxydehydrogenation and the selectivities of products on $\mathrm{Pt} / \mathrm{BN}$. The conversion is maintained near $17-19 \%$ while propylene selectivity was only $33 \%$. The molar ratio of methane to $\mathrm{C} 2$ (ethane and ethylene) is close to one due to the cracking of propane. Most of ethane is further oxydehydrogenated to ethylene, where selectivity is near $30 \%$.

The conversions and selectivities on $\mathrm{Pt}-\mathrm{Sn}(0.75) / \mathrm{BN}$ is shown in Fig. 6, which gave the best performance in the series of Pt$\mathrm{Sn} / \mathrm{BN}$ catalysts. Compared with monometallic Pt/BN catalyst (Fig. 5), both conversion and propylene selectivity are signifi-

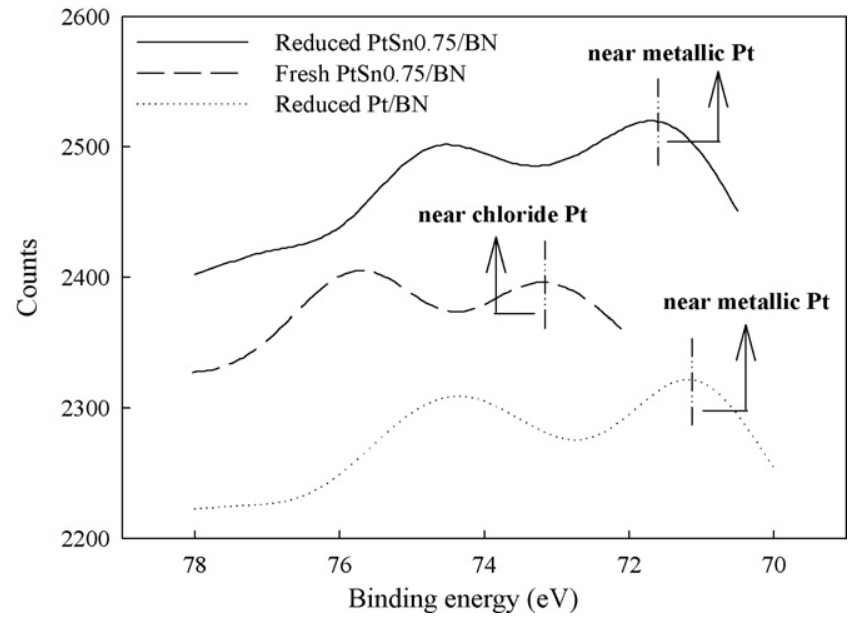

Fig. 4. XPS of Pt $4 \mathrm{f}$ on $\mathrm{BN}$ support. 


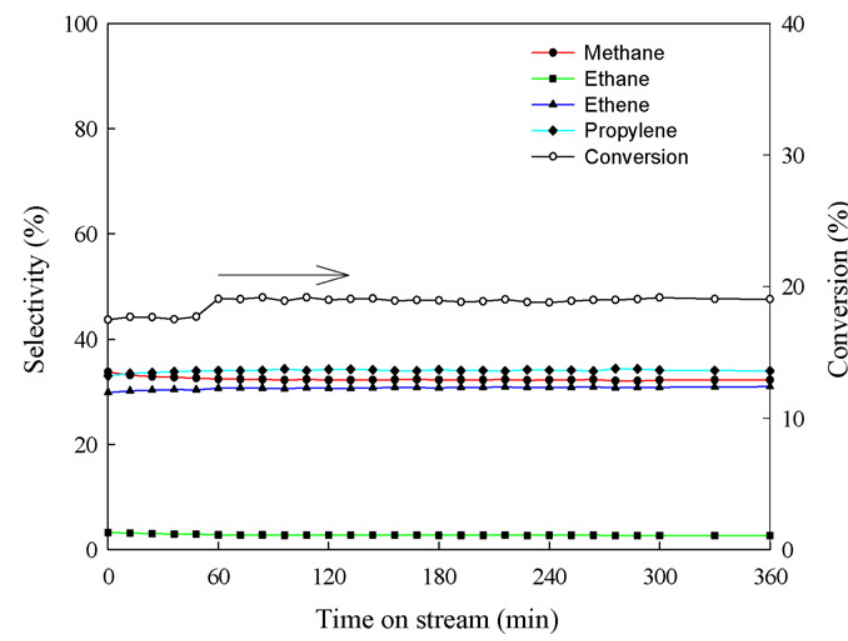

Fig. 5. Oxydehydrogenation of propane on $\mathrm{Pt} / \mathrm{BN}$ at $600{ }^{\circ} \mathrm{C}$ (catalyst weight $0.3 \mathrm{~g}, 1 \mathrm{~atm}$, flow rate $=23.75 \mathrm{ml} / \mathrm{min}, \mathrm{C}_{3} \mathrm{H}_{8} / \mathrm{Air}=8 / 2$ ).

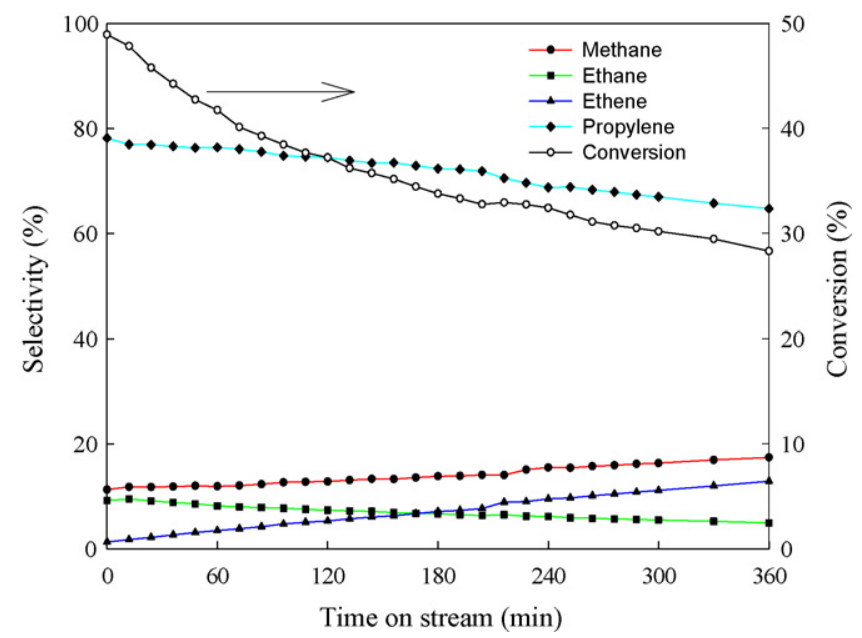

Fig. 6. Oxydehydrogenation of propane on $\mathrm{Pt}-\mathrm{Sn}(0.75) / \mathrm{BN}$ at $600{ }^{\circ} \mathrm{C}$ (catalyst weight $0.3 \mathrm{~g}, 1 \mathrm{~atm}$, flow rate $=23.75 \mathrm{ml} / \mathrm{min}, \mathrm{C}_{3} \mathrm{H}_{8} / \mathrm{Air}=8 / 2$ ).

cantly improved concurrently. The cracking of propane is also depressed as indicated by the decreasing selectivities of methane and ethane. However, on Pt-Sn(0.75)/BN, the conversions gradually decrease from 49 to $28 \%$, and the propylene selectivities also slightly decline from 79 to $64 \%$ in 6-h reaction. A small of

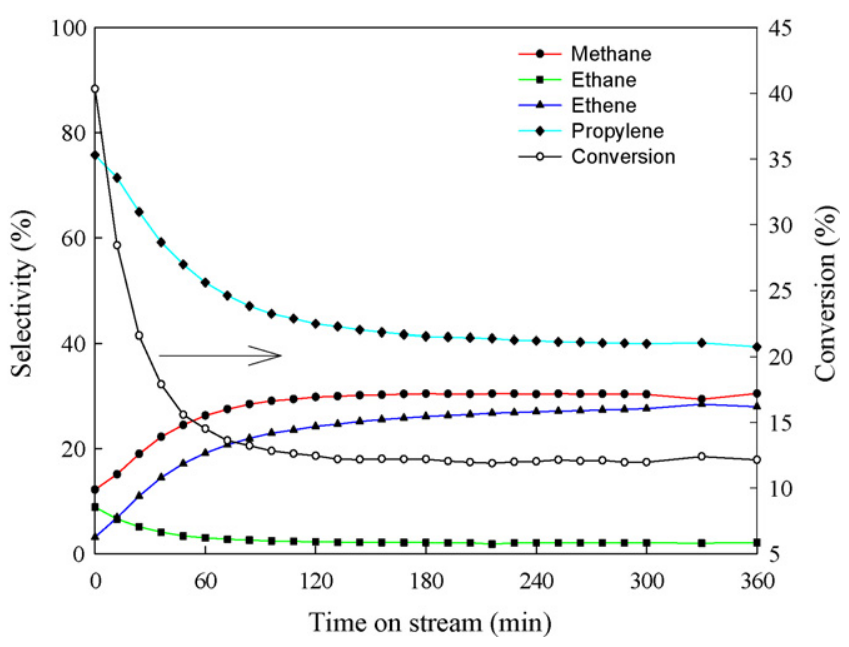

Fig. 7. Oxydehydrogenation of propane on $\mathrm{Pt}-\mathrm{Sn}(0.5) / \gamma-\mathrm{Al}_{2} \mathrm{O}_{3}$ at $600{ }^{\circ} \mathrm{C}$ (catalyst weight $0.3 \mathrm{~g}, 1 \mathrm{~atm}$, flow rate $=23.75 \mathrm{ml} / \mathrm{min}, \mathrm{C}_{3} \mathrm{H}_{8} / \mathrm{Air}=8 / 2$ ).

amount of coke may be still accumulated so that the activity is gradually decreased. Fig. 7 shows the conversion and propylene selectivity of Pt-Sn(0.5)/ $\gamma-\mathrm{Al}_{2} \mathrm{O}_{3}$, which gave the best performance in the series of $\mathrm{Pt}-\mathrm{Sn} / \gamma-\mathrm{Al}_{2} \mathrm{O}_{3}$ catalysts. Its conversion quickly decreased from 40 to $12 \%$, and propylene selectivity also declined from 76 to $40 \%$.

Table 2 summarizes the initial and final conversions and selectivities on all Pt and Pt-Sn on BN and $\gamma-\mathrm{Al}_{2} \mathrm{O}_{3}$ catalysts in 6-h reaction. In general, the conversions and selectivities gradually decreased for the period of oxydehydrogenation in all catalysts. The initial conversion of $\mathrm{Pt} / \gamma-\mathrm{Al}_{2} \mathrm{O}_{3}(35 \%)$ is much higher than that of $\mathrm{Pt} / \mathrm{BN}(17.4 \%)$ because of a high Pt dispersion on $\gamma-\mathrm{Al}_{2} \mathrm{O}_{3}$ (Table 1). However, the conversion and propylene yield of $\mathrm{Pt} / \gamma-\mathrm{Al}_{2} \mathrm{O}_{3}$ decrease to near those of $\mathrm{Pt} / \mathrm{BN}$ due to coking after $50 \mathrm{~min}$ of reaction.

As shown in Table 2, the propylene selectivities on bimetallic Pt-Sn are all higher than those of monometallic Pt catalysts, whether on $\mathrm{BN}$ or $\gamma-\mathrm{Al}_{2} \mathrm{O}_{3}$. The un-desired products, methane, ethane and ethylene, are significantly suppressed using Pt-Sn catalysts. The highest yield of propylene is on $\mathrm{Pt}-\mathrm{Sn}(0.75) / \mathrm{BN}$ which starts from $38.3 \%$ then decreases to $18.3 \%$ during $6 \mathrm{~h}$. Overall, the yields of propylene on $\mathrm{Pt}-\mathrm{Sn} / \mathrm{BN}$ are higher than those of Pt-Sn/ $\gamma-\mathrm{Al}_{2} \mathrm{O}_{3}$. The propylene selectivity is not strongly influenced by the amount of Sn loadings on BN. Obviously,

Table 2

Oxidative dehydrogenation of propane at $600{ }^{\circ} \mathrm{C}$

\begin{tabular}{|c|c|c|c|c|c|c|c|c|}
\hline Catalyst & $\mathrm{Sn} / \mathrm{Pt}$ & $X^{0}(\%)$ & $X^{\mathrm{f}}(\%)$ & $S^{0}(\%)$ & $S^{\mathrm{f}}(\%)$ & $Y^{0}(\%)$ & $Y^{f}(\%)$ & Stability \\
\hline $\mathrm{Pt} / \mathrm{BN}$ & 0 & 17.4 & 19 & 33.1 & 34 & 5.8 & 6.5 & 1.09 \\
\hline $\mathrm{Pt}-\mathrm{Sn}(0.25) / \mathrm{BN}$ & 0.37 & 42.9 & 18 & 73.9 & 37.3 & 31.7 & 6.7 & 0.42 \\
\hline $\mathrm{Pt}-\mathrm{Sn}(0.50) / \mathrm{BN}$ & 0.75 & 47.4 & 19.6 & 79.2 & 53 & 37.6 & 10.4 & 0.41 \\
\hline $\mathrm{Pt}-\mathrm{Sn}(0.75) / \mathrm{BN}$ & 1.12 & 48.9 & 28.3 & 78.2 & 64.7 & 38.3 & 18.3 & 0.58 \\
\hline $\mathrm{Pt} / \gamma-\mathrm{Al}_{2} \mathrm{O}_{3}$ & 0 & 35.0 & 14.2 & 43.6 & 40 & 15.2 & 5.7 & 0.41 \\
\hline $\mathrm{Pt}-\mathrm{Sn}(0.25) / \gamma-\mathrm{Al}_{2} \mathrm{O}_{3}$ & 0.37 & 29.4 & 13.3 & 71.2 & 38.5 & 20.9 & 5.1 & 0.45 \\
\hline $\mathrm{Pt}-\mathrm{Sn}(0.50) / \gamma-\mathrm{Al}_{2} \mathrm{O}_{3}$ & 0.75 & 40.3 & 12.1 & 75.8 & 39.4 & 30.6 & 4.8 & 0.3 \\
\hline $\mathrm{Pt}-\mathrm{Sn}(0.75) / \gamma-\mathrm{Al}_{2} \mathrm{O}_{3}$ & 1.12 & 15.2 & 14.7 & 45.6 & 37.5 & 6.9 & 5.5 & 0.97 \\
\hline
\end{tabular}

$X^{0}$ : initial propane conversion and $S^{0}$ : initial selectivity to propylene (measured at $10 \mathrm{~min}$. of the reaction time). $X^{\mathrm{f}}$ : final propane conversion and $S^{\mathrm{f}}$ : final selectivity to all propylene (measured at $6 \mathrm{~h}$ of the reaction time). $Y^{0}$ and $Y^{\mathrm{f}}$ : initial and final yields to propylene (calculated as the product of the conversion and the selectivity to propylene), respectively. Stability: $X^{\mathrm{f}} / X^{0}$. 
Table 3

Carbon balance in oxydehydrogenation

\begin{tabular}{lc}
\hline Catalysts & Initial carbon balance $(\%)$ \\
\hline $\mathrm{Pt} / \mathrm{BN}$ & -4.7 \\
$\mathrm{Pt}-\mathrm{Sn}(0.25) / \mathrm{BN}$ & -14.6 \\
$\mathrm{Pt}-\mathrm{Sn}(0.50) / \mathrm{BN}$ & -21.5 \\
$\mathrm{Pt}-\mathrm{Sn}(0.75) / \mathrm{BN}$ & -20.6 \\
$\mathrm{Pt} / \gamma-\mathrm{Al}_{2} \mathrm{O}_{3}$ & -24.6 \\
$\mathrm{Pt}-\mathrm{Sn}(0.25) / \gamma-\mathrm{Al}_{2} \mathrm{O}_{3}$ & -18.8 \\
$\mathrm{Pt}-\mathrm{Sn}(0.50) / \gamma-\mathrm{Al}_{2} \mathrm{O}_{3}$ & -22.7 \\
$\mathrm{Pt}-\mathrm{Sn}(0.75) / \gamma-\mathrm{Al}_{2} \mathrm{O}_{3}$ & -5.8 \\
\hline
\end{tabular}

Sn plays an important role in oxydehydrogenation, especially in propylene selectivity. The stability of catalysts indicates the deactivation during 6-h oxydehydrogenation. By and large, the stabilities of $\mathrm{Pt}-\mathrm{Sn} / \mathrm{BN}$ are slightly better than those of Pt$\mathrm{Sn} / \gamma-\mathrm{Al}_{2} \mathrm{O}_{3}$. Therefore, the propane oxydehydrogenation of $\mathrm{Pt}-\mathrm{Sn} / \mathrm{BN}$ outperforms that of $\mathrm{Pt}-\mathrm{Sn} / \gamma-\mathrm{Al}_{2} \mathrm{O}_{3}$.

Part of propane and its products are oxidized to $\mathrm{CO}_{2}$ and $\mathrm{H}_{2} \mathrm{O}$. Such loss is presented by a overall carbon loss measured in the experiments. Table 3 summarizes the overall carbon loss of all catalysts at the beginning of oxydehydrogenation. The difference of carbon loss between the $\mathrm{BN}$ and $\gamma-\mathrm{Al}_{2} \mathrm{O}_{3}$ supports is not notable. In general, near $6-25 \%$ carbon is burned out during the oxydehydrogenation. The carbon loss on $\mathrm{Pt} / \mathrm{BN}$ is much less than $\mathrm{Pt} / \gamma-\mathrm{Al}_{2} \mathrm{O}_{3}$ revealing over-oxidation due to a highly dispersed $\mathrm{Pt}$ on $\gamma-\mathrm{Al}_{2} \mathrm{O}_{3}$.

The effect of reaction temperature was further studied on $\mathrm{Pt}-\mathrm{Sn}(0.75) / \mathrm{BN}$ at $500^{\circ} \mathrm{C}$, as shown in Fig. 8. The conversion decreases at lower temperature as expected, and propylene selectivity significantly increases to above $90 \%$. Meanwhile the deactivation becomes much slower at $500^{\circ} \mathrm{C}$.

The selectivity enhancement of propylene in the oxydehydrogenation is attributed to the formation of PtSn alloy particles on $\mathrm{BN}$ support. Both $\mathrm{Pt}$ and $\mathrm{SnPt}_{3}$ alloy are formed at low $\mathrm{Sn}$ loading, while only PtSn is found at a higher Sn loading on BN support (Fig. 1). Boron nitride provides an inert and slippery surface that facilitates the formation of PtSn alloy during $\mathrm{H}_{2}$

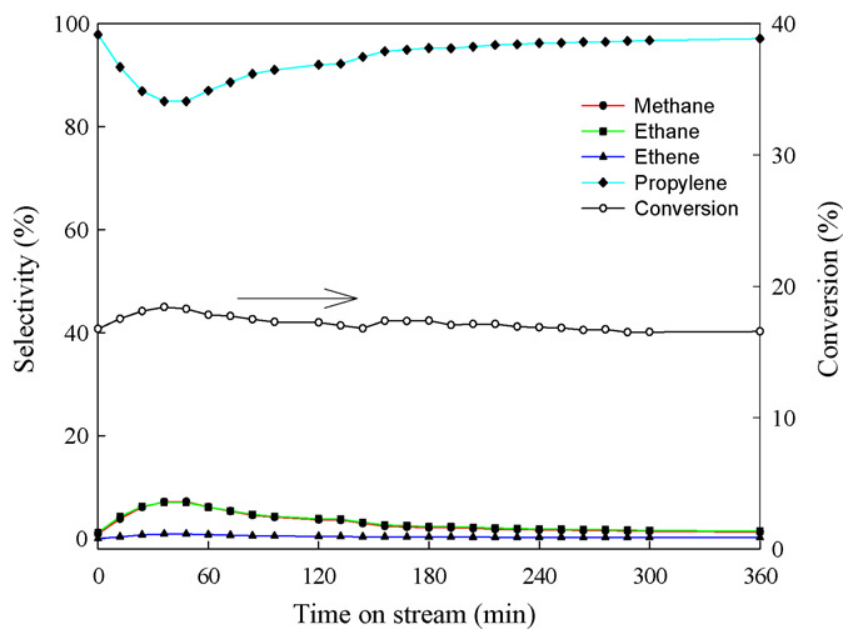

Fig. 8. Oxydehydrogenation of propane on $\mathrm{Pt}-\mathrm{Sn}(0.75) / \mathrm{BN}$ at $500{ }^{\circ} \mathrm{C}$ (catalyst weight $0.3 \mathrm{~g}, 1 \mathrm{~atm}$, flow rate $=23.75 \mathrm{ml} / \mathrm{min}, \mathrm{C}_{3} \mathrm{H}_{8} / \mathrm{Air}=8 / 2$ ). reduction due to the unrestrained migration of metal particles. On the other hand, $\gamma-\mathrm{Al}_{2} \mathrm{O}_{3}$ may constrain the mobility of $\mathrm{Pt}$ and $\mathrm{Sn}$ during $\mathrm{H}_{2}$ reduction due to the metal-support affinity, thus preventing the formation of PtSn alloy particles.

The PtSn alloy particle possessed surface $\mathrm{Pt}^{\circ}$ and partially covered with $\mathrm{Sn}^{2+}$ on $\mathrm{BN}$ support is proposed to be the origin to improve the selectivity of propylene and the activity in oxydehydrogenation. Surface Pt plays a major role in the oxydehydrogenation due to its capability of propane and oxygen adsorptions. Sn addition covers a portion of surface Pt, thus suppresses the activity of cracking to form methane and ethane/ethylene, as well as the over-oxidation of propane and propylene.

Unlike $\gamma-\mathrm{Al}_{2} \mathrm{O}_{3}$ with a hydrophilic surface, the hydrophobicity of $\mathrm{BN}$ may be a favorable property in oxydehydrogenation. One of the products, water vapor, can be easily expelled from the surface or pores on $\mathrm{BN}$ resulting in a higher activity than that on $\gamma-\mathrm{Al}_{2} \mathrm{O}_{3}$.

\section{Conclusion}

This study has presented favorable findings for the oxydehydrogenation of propane into propylene by employing $\mathrm{BN}$ supported PtSn catalysts. Compared with the traditional $\gamma$ $\mathrm{Al}_{2} \mathrm{O}_{3}$ support, $\mathrm{BN}$ exhibits an unique property of minimum metal-support interference thus PtSn alloy can be formed easily during $\mathrm{H}_{2}$ reduction. The selectivity of propylene is greatly improved without sacrificing the conversion in oxydehydrogenation. Coking is possibly reduced on $\mathrm{BN}$ due to the lack of acidity. Therefore, boron nitride offers a promising support for oxydehydrogenation catalyst.

\section{Acknowledgement}

The authors would like to thank the National Science Council of the Republic of China, Taiwan for financially supporting this research under Contract No. NSC-94-2214-E-002-029.

\section{References}

[1] M.M. Bhasin, J.H. McCain, B.V. Vora, T. Imai, P.R. Pujadó, Appl. Catal. A: Gen. 221 (2001) 397-419.

[2] D.L. Stern, R.K. Grasselli, J. Catal. 167 (1997) 570-572.

[3] B. Solsona, A. Dejoz, M.I. Vázquez, F. Márquez, J.M. López Nieto, Appl. Catal. A: Gen. 208 (2001) 99-110.

[4] K. Nowinska, A. Waclaw, A. Izbinska, Appl. Catal. A: Gen. 243 (2003) 225-236

[5] O.A. Bariås, A. Holmen, E.A. Blekkan, J. Catal. 158 (1996) 1-12.

[6] J. Salmones, J.A. Wang, J.A. Galicia, G. Aguilar-Rios, J. Mol. Catal. A: Chem. 184 (2002) 203-213.

[7] S.B. Kogan, M. Herskowitz, Catal. Commun. 2 (2001) 179-185.

[8] D. Akporiaye, S.F. Jensen, U. Olsbye, F. Rohr, E. Rytter, M. Rønnekleiv, A.I. Spjelkavik, Ind. Eng. Chem. Res. 40 (2001) 4741-4748.

[9] Z.-A. Lin, J.C.S. Wu, J.-W. Pan, C.-T. Yeh, J. Catal. 210 (2002) 39-45.

[10] J.C.S. Wu, Y.-C. Fan, C.-A. Lin, Ind. Eng. Chem. Res. 42 (2003) 3225-3229.

[11] S. Alkoy, C. Toy, T. Gonul, A. Tekin, J. Eur. Ceram. Soc. 17 (1997) 1415.

[12] M. Englisch, V.S. Ranade, J.A. Lercher, J. Mol. Catal. A: Chem. 121 (1997) 69.

[13] F. Delbecq, P. Sautet, J. Catal. 164 (1996) 152. 
[14] J.C.S. Wu, W.-C. Chen, Appl. Catal. A: Gen. 289 (2005) 179.

[15] J.C.-S. Wu, Z.-A. Lin, J.-W. Pan, M.-H. Rei, Appl. Catal. A: Gen. 219 (2001) 117.

[16] International Centre for Diffraction Data (JCPDS-ICDD PDF-2 Database version 2.15), Academia Sinica (1987).
[17] J.F. Moulder, W.F. Stickle, P.E. Sobol, K.D. Bombem, Handbook of X-Ray Photoelectron Spectroscopy, Physical Electronic Inc., Eden Prairie, MN, 1995.

[18] D.I. Jerdev, B.E. Koe, Surf. Sci. 513 (2002) L391. 